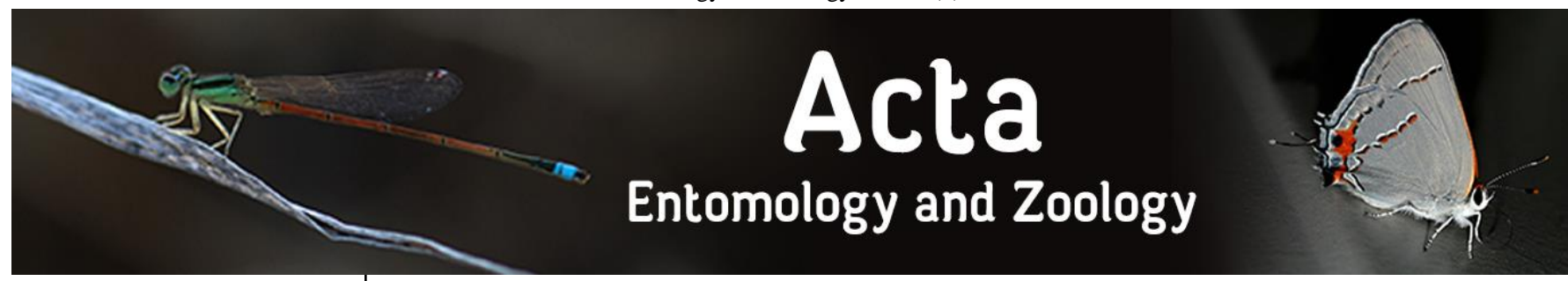

E-ISSN: 2708-0021 P-ISSN: 2708-0013 www.actajournal.com AEZ 2020; 1(1): 44-45 Received: 13-10-2019 Accepted: 14-11-2019

Jayaraman Dharmaraj Department of Zoology, Bharathiar University Coimbatore, Tamil Nadu, India

Chinnappan Gunasekaran Department of Zoology, Bharathiar University, Coimbatore, Tamil Nadu, India

Vallavan Rajkumar Department of Zoology, Bharathiar University, Coimbatore, Tamil Nadu, India

Cheruvarthy Amita Paul Department of Zoology, Bharathiar University, Coimbatore, Tamil Nadu, India
Corresponding Author: Jayaraman Dharmaraj Department of Zoology, Bharathiar University, Coimbatore, Tamil Nadu, India

E-mail: dharmaraj590@gmail.com

\section{The first report of the Cheiracanthium melanostomum (Thorell, 1895) from the Nilgiris, Tamil Nadu, India}

\section{Jayaraman Dharmaraj, Chinnappan Gunasekaran, Vallavan Rajkumar and Cheruvarthy Amita Paul}

DOI: https://doi.org/10.33545/27080013.2020.v1.i1a.8

\section{Abstract}

Sac-spiders (Family: Clubionidae) are one of the common predators of insect pests in the cropfields and gardens. The spider s of the genus Clubiona are practically unknown of the Indian Fauna. Very little in formations are available on this group of spiders in Bangladesh (Chowdhury \& Pal, 1984; Biswas, et. ai., 1993; Okuma, et. al., 1993; Begum \& Biswas, 1997; Biswas \& Raychaudhuri, 1994) although a great number of works took place in Indian Sub-continent and elsewhere (Platnick \& Shadab, 1974a, b; Reiskind, 1969; Roberta, 1985; Chen \& Zhang, 1989; Koh, 1989; Yaginuma, 1986).

Keywords: Sac spider, predators, pests

\section{Introduction}

The specimens were studied in the Department of Zoology, Bharathiar University, Coimbatore. All measurements are in mm by using a Stereo Microscope and DSLR Camera. Spiders to be preserved in rectified spirit with a few drops of glycerin in collection vials.

Type species: Cheiracanthium melanostomum

\section{Material Exmined}

On 13.09.2019 at during a field visit in Emerald Valley $\left(11.342908^{\circ} \mathrm{N}, 76.598176^{\circ} \mathrm{E}\right)$, Nilgiris, Tamil Nadu, India. We observed a live specimen of Cheiracnthium melanostomum.

\section{General Description}

Cephalothorax yellowish, dorsum convex, anterior part narrower, broadest in the posterior half. Total length of Female $6.12 \mathrm{~mm}$, Carapace length $2.85 \mathrm{~mm}$; carapace width $2.25 \mathrm{~mm}$. Abdomen length $3.95 \mathrm{~mm}$; abdominal width $2.72 \mathrm{~mm}$; Spinnerets yellowish, posterior spinnerets much longer palp tarsal, apophysis slender (Fig 1).

\section{Natural History}

This nocturnal spider hides during the day in a silken retreat usually placed on the underside of leaves of broad leafed. Sometimes in dead leaves,

\section{Distribution}

India, Bangladesh, Myanmer 


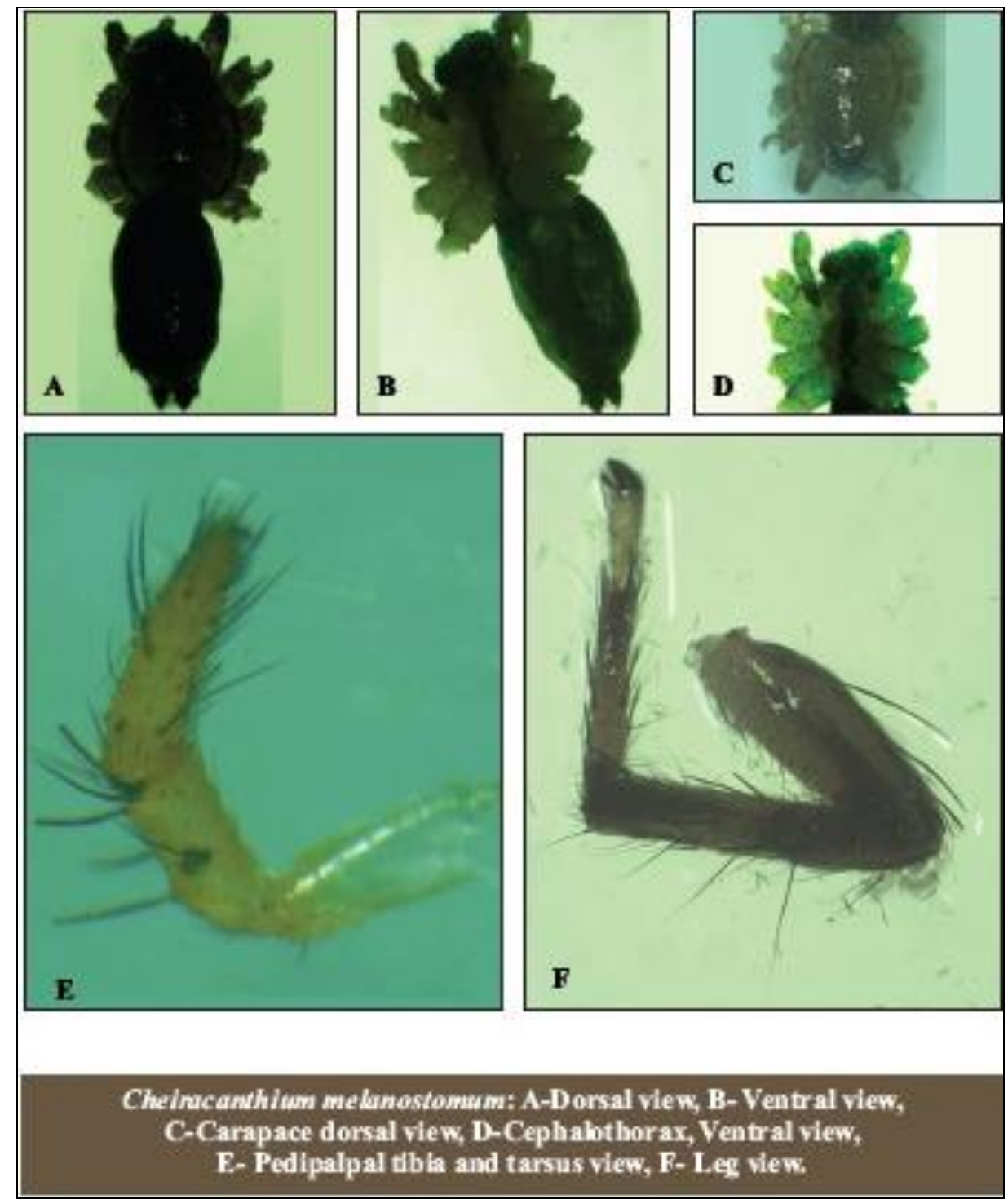

Fig 1: Cheiracanthium melanostomum

\section{References}

1. Begum A, Biswas V. A list of the spider fauna of Barisal division, Bangladesh (Araneae: Arachnida). Bangladeshi. zoo. 1997; 25(2):207-210.

2. Biswas V, Raychaudhuri D. Clubionid spiders of Bangladesh-I: Genus Clubiona Latreille. Proc. Recent Adv. LIfe Sc., Dibrugarh. 1994; 1:191-210.

3. Biswas V, Khan HR, Kamal NQ, Begum A. A preliminary study of the rice-field spiders in Jhenidah, Bangladesh. Bangladesh j. Zool. 1993; 21:85-92.

4. Chen ZF, Zhang ZH. Fauna of Zhejiang, Araneida. Zheiiang Sci. \& Tech. Pub. House. 1989, 356.

5. Chowdhury SH, Pal SK. Further report on rice-field spiders from Bangladesh. Chittagong Univ. Studies, II, 1984; 8:25-39.

6. Koh JKH. A Guide to Singapore spiders. Singapore Science Centre. 1989, 160.

7. Majumder, Tikader, Sebastian \& Peter, 2009; Keswani et al., 2012; Saha \& Raychaudhuri, 2015; Sen et al., 2015; WSC, 2016), 1991.

8. Okuma C, Kamal NQ, Hirashima Y, Alam Z, Ogata T. Illustrated Monograph on the spiders of Bangladesh. IPSA-JAICA, Salna, Gazipur. 1993, 1-93.

9. Platnick NI, Shadab SU. A revision of the bispinosus and bieolor groups of the spider genus Trachelas
(Araneae: Clubionidae) in North and Central America and West Indies. Am. Mus. Novit. 1974; 2560:1-34.

10. Reiskind J. The spider sub-family Castianeirinae of North and Central America (Araneae: Clubionidae). Bull. Mus. Compo Zool. Harv. 1969; 138:162-325.

11. Roberts MJ. The spiders of Great Bretain and Ireland. Harely Books, Colchester 1985; I(II):1-204.

12. Yaginuma T. spiders of Japan in colour (new ed.). Hoikusha Pub. Co., Osaka, 1986, 305. 